\title{
Implementation of Facebook study groups as supplements for learning management systems in adult ODL environments
}

\author{
Ishan Sudeera Abeywardena \\ Wawasan Open University, Malaysia \\ Tham Choy Yoong \\ Wawasan Open University, Malaysia
}

\begin{abstract}
As an open and distance learning (ODL) institution, Wawasan Open University (WOU) employs a blended approach for delivering courses to its undergraduate and postgraduate students, who are entirely adult learners. In this approach, the use of a learning management system (LMS) is absolutely crucial for student support as well as the enhancement of the whole learning experience to compensate for the lack of face-to-face interaction between the students and the academics. WawasanLearn, the open source, Moodle-based LMS system used by WOU, is a comprehensive online tool that enables students and academics to effectively interact in a virtual environment. However, analysis of data from several semesters shows that the rate of student interaction on WawasanLearn is low with respect to the sharing of knowledge.
\end{abstract}

In order to qualitatively and quantitatively identify the factors contributing to the student participation rate in WawasanLearn, a survey was conducted among the undergraduate students studying in various disciplines including science and technology, business administration, liberal studies, education, languages and communication. Feedback regarding the manner of support students expect from WawasanLearn was gathered from close to 550 students throughout Malaysia. Another purpose of the survey was to identify whether and why students are drawn to participate more frequently in social networking platforms such as Facebook (facebook.com).

As a result of the findings of the survey, a pilot project was implemented to study the use of Facebook groups as study groups for supplementing WawasanLearn. These study groups were run in parallel to WawasanLearn for seven course modules over two consecutive semesters. This paper discusses the findings of this pilot project with respect to the implementation of Facebook groups as supplements to the LMS in an adult ODL environment.

Keywords: Social networking, Facebook, Moodle, open distance learning, ODL, learning management systems 


\section{Introduction}

The core business of Wawasan Open University (WOU) is open distance learning (ODL). The students of WOU are mostly working adults who pursue undergraduate and postgraduate degree programmes on a part-time basis in disciplines such as science and technology, business administration, education, languages and liberal studies. WOU adopts a blended approach for course module delivery. Due to the limitations in technology infrastructure such as the bandwidth in the Asian region (Bates, 2001), self-directed learning materials are provided to the students on CDs together with prescribed textbooks. The continuous academic interaction between teachers and learners is facilitated by a Moodle (version 1.8)-based learning management system (LMS) named WawasanLearn.

The course module delivery at WOU consists of two components: (i) self-study using selfdirected study materials specifically designed for ODL by academics functioning as course coordinators and instructional designers working in course development teams; and (ii) tutor support provided by subject-matter experts through monthly face-to-face tutorial sessions, telephone counselling and online counselling via WawasanLearn. As the students of WOU are scattered throughout Malaysia, the university operates learning centres or regional offices in the cities of Penang, Kuala Lumpur, Ipoh, Johor Baru, Kota Baru and Kuching to provide students access to physical libraries, tutorial sessions as well as administrative support. However, due to the geographic distribution of the learners, the primary point of continuous interaction among students, tutors and course coordinators is WawasanLearn.

Given the importance of WawasanLearn in the course module delivery at WOU, a number of studies have been conducted to determine whether student interaction is at a satisfactory level. Teoh et al. (2010) argue that student interaction on WawasanLearn, in both the undergraduate and postgraduate levels, is low and further reduces as a semester progresses. Looking at other ODL institutions around the world, it becomes apparent that many of these institutions are heavily dependent on online student support systems for the effective delivery of course modules (Macintyre \& Macdonald, 2011) and that the lack of participation and interaction in online LMS is not a problem unique to WOU. According to Mason and Weller (2000), established distance learning institutions such as the Open University of UK also face low numbers when it comes to such participation.

As a possible solution for the low rates of participation on dedicated student support channels, more and more institutions have started looking at Web 2.0 technologies and social networking to include the "always on" learner (Baird \& Fisher, 2006). Wang et al. (2003) suggest that learner interaction on social networks becomes easier because the profile of each learner acts as an icebreaker for the interaction. It was also found that forming small study groups in more informal spaces is conducive to the progress of the student (Stacy, 2002). 
Facebook has become a popular social networking platform in recent years and many studies have been done on its potential use in a formal learning environment. As discussed by Madgea et al. (2009), learners form connections with peers on Facebook prior to joining higher educational institutions and tend to use it even more after joining. Learners even seem to gain self-esteem and confidence through the use of Facebook (Ellison, Steinfield \& Lampe, 2007). Ophus and Abbitt (2009) have found that many learners find use for Facebook in their learning with respect to the ease and convenience of communication. It was also found that learners tend to communicate and perform more as a response to self-disclosure of teachers on Facebook (Mazer, Murphy \& Simonds, 2007).

The literature suggests that quite a number of studies on the use of Facebook by students have been conducted in recent times. However, the possibility of supplementing the official LMS of a university with Facebook has not been studied in detail. This research project attempts to marry WawasanLearn and Facebook in a real-world learning environment to fulfil the learning needs of adult ODL students.

\section{Methodology}

The continuous interaction via WawasanLearn is critical for the successful delivery of course modules at WOU. To identify (i) how useful WawasanLearn is in terms of fulfilling students' learning needs, and (ii) why students are drawn to participate more frequently in social networking forums such as Facebook, a survey was conducted online as well as offline in all WOU regional offices in Malaysia. The survey collected 542 responses from undergraduate students in various disciplines.

The survey instrument was designed to identify (i) features which would increase the frequency of logins into WawasanLearn; (ii) the extent of Facebook use by adult ODL learners; and (iii) which features of Facebook attract adult ODL learners to log on to it frequently. 


\section{Results}

\section{Features which would increase the frequency of logins onto WawasanLearn}

A frequency analysis of the data was done to identify the features that would encourage students to $\log$ in more into WawasanLearn. Figure 1 arranges the features listed in Table 1 in descending order of importance according to the number of student responses.

\begin{tabular}{|c|l|}
\hline Legend & \multicolumn{1}{|c|}{ Feature } \\
\hline A & $\begin{array}{l}\text { More interactive and exciting material (video, images, animations, e-books, audio } \\
\text { books and so on). }\end{array}$ \\
\hline B & $\begin{array}{l}\text { More quality discussions (the course coordinators and tutors initiating discussions } \\
\text { about current happenings in the industry/research with respect to the course). }\end{array}$ \\
\hline C & $\begin{array}{l}\text { Faster response time (course coordinators and tutors responding to students } \\
\text { faster). }\end{array}$ \\
\hline D & A better user interface (a more appealing and user-friendly interface). \\
\hline E & $\begin{array}{l}\text { The ability to read about or view the research/other academic/professional } \\
\text { activities of course coordinators, tutors and colleagues. }\end{array}$ \\
\hline F & $\begin{array}{l}\text { A more intuitive and user-friendly chat application which can be used through the } \\
\text { LMS system. }\end{array}$ \\
\hline G & $\begin{array}{l}\text { A proactive approach to discussions - students receive an e-mail/SMS as soon as a } \\
\text { new message is posted. }\end{array}$ \\
\hline
\end{tabular}

Table 1 The list of features

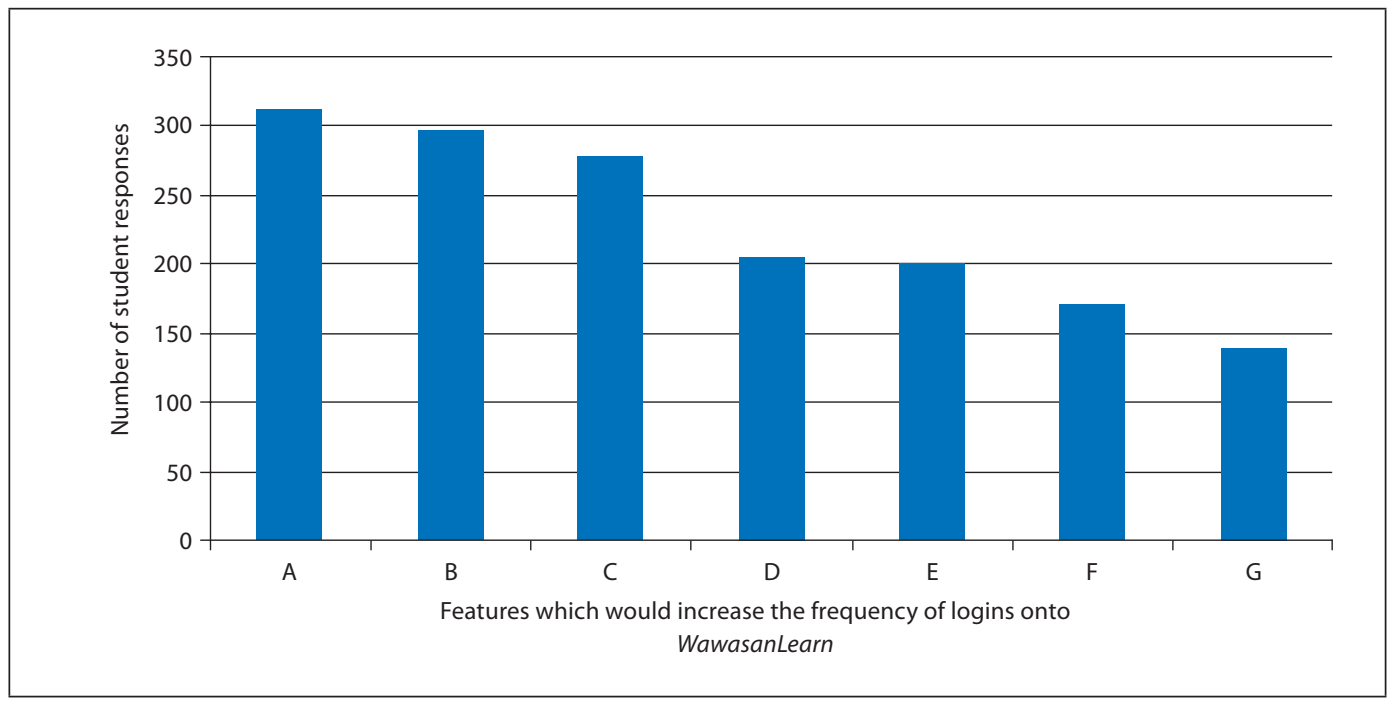

Figure 1 The features of WawasanLearn which would increase the frequency of logins (in descending order according to the number of responses) 


\section{Extent of the use of Facebook by learners at WOU}

Analysis of the survey results revealed that $83 \%$ of the students subscribed to Facebook. A frequency analysis of the number of logins into Facebook per week, shown in Figure 2, revealed that $70 \%$ of the students who subscribed to Facebook log in at least three days a week. Analysis of the number of logins into WawasanLearn for the Facebook subscribers, shown in Figure 3, revealed that only 51\% logged into WawasanLearn more than three days a week. This comparison indicates that there is a possibility of increasing teacher-learner interaction if Facebook is used as the medium for it.

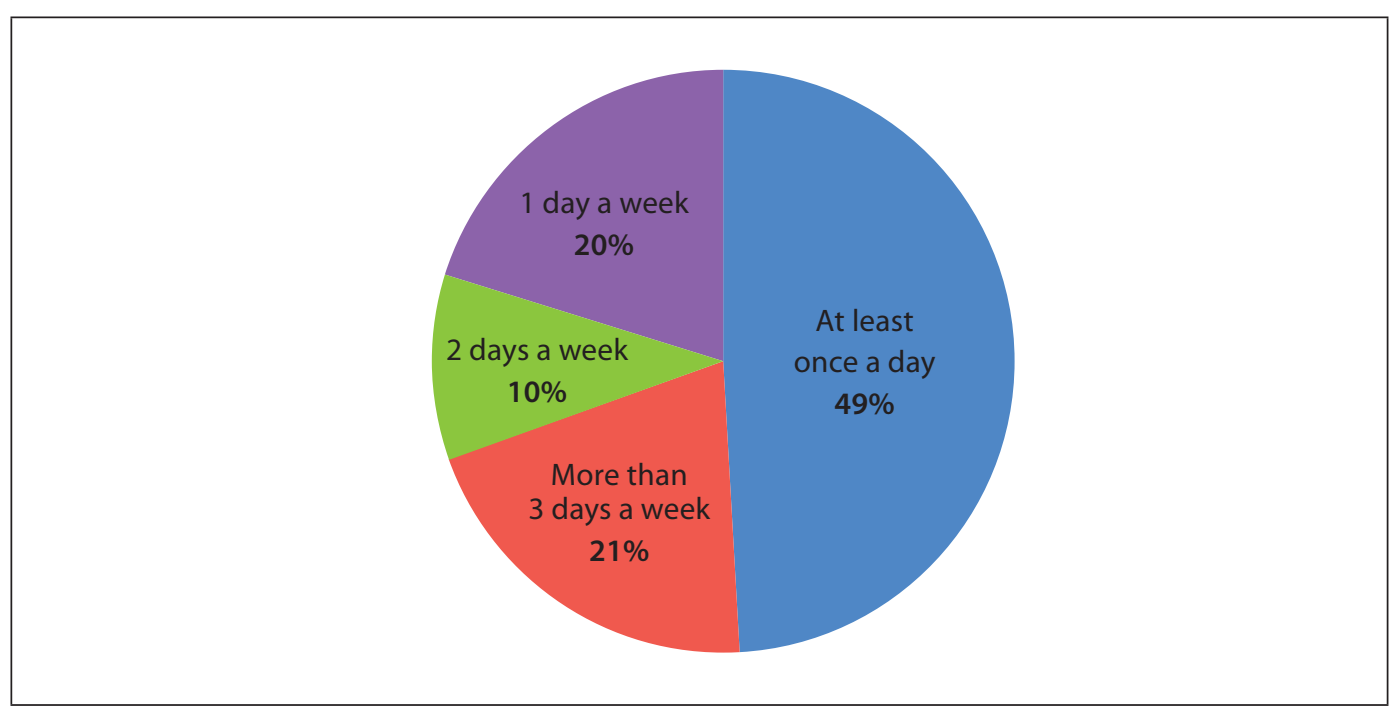

Figure 2 Frequency of logins into Facebook

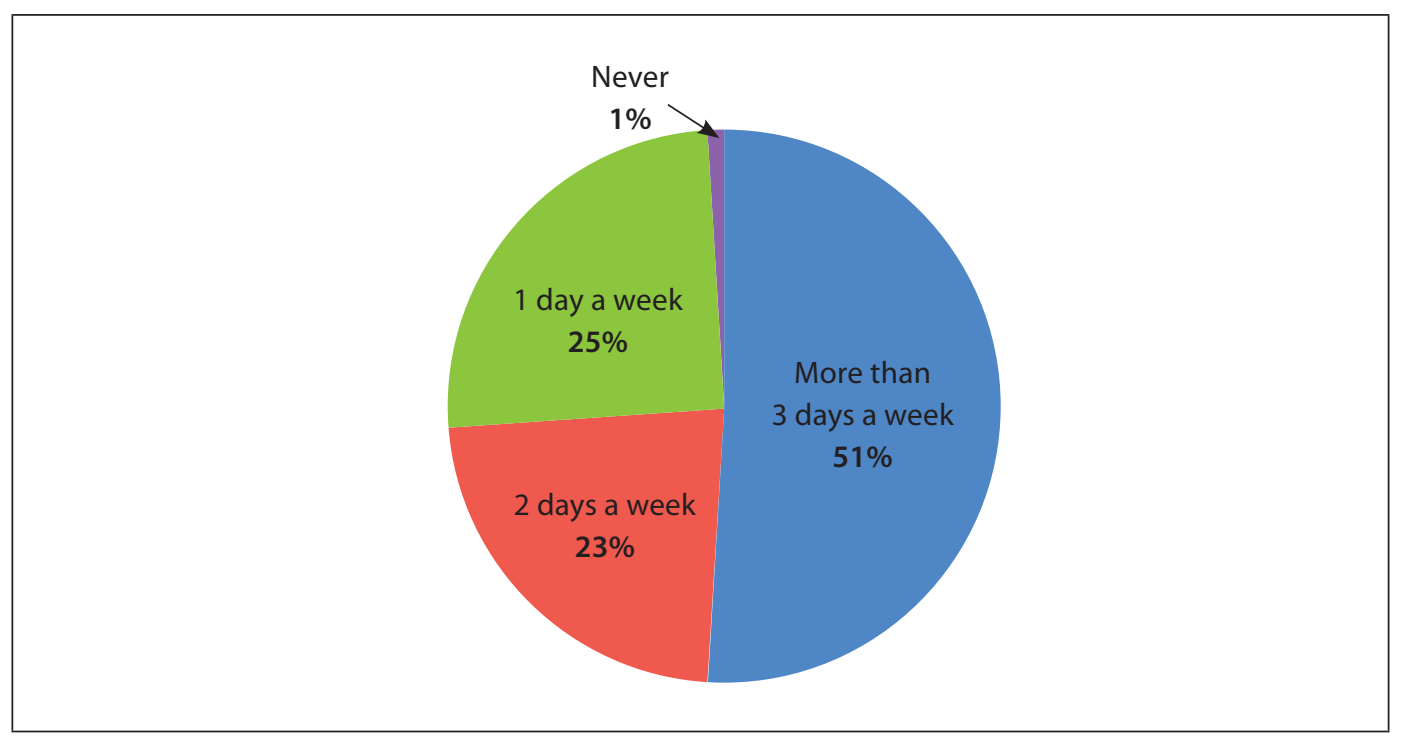

Figure 3 Frequency of logins into WawasanLearn by Facebook subscribers 
The following are the key attractions of Facebook which were identified from the students' feedback:

- The ability to interact with friends, colleagues and family in a virtual space.

- Instant updates via e-mails and SMS with respect to related activities.

- User-friendly interface which is easy to navigate.

- The ability to follow the progress of friends and colleagues with respect to research and work.

- The ease of organising events and inviting friends and colleagues to participate.

- The ability to share images, links and videos easily and the ability to receive comments on them.

- The ability to send out messages to an individual or a group from within Facebook.

- The ability to view the profiles of friends and colleagues.

- The ability to see who is online and instantly chat with them.

\section{Discussion}

To effectively increase the frequency of logins into WawasanLearn, the important features identified in Table 1 will need to be incorporated into the LMS. The current WawasanLearn system, based on the Moodle (1.8) platform, was found to be incapable of effectively addressing these requirements independently. As this was the version of Moodle implemented at WOU during this study, the necessity for identifying an external platform which could supplement WawasanLearn became apparent.

Since $83 \%$ of the students who participated in the study were subscribers of Facebook and $70 \%$ of them interacted on it more than three days a week (Figure 2), in contrast to the $51 \%$ who interacted on WawasanLearn (Figure 3), Facebook was found to be a suitable candidate to supplement WawasanLearn. By comparing the top four features that would increase the frequency of logins into WawasanLearn against the key attractions of Facebook, it can be deduced that all the key features which are currently lacking in WawasanLearn can be provided by Facebook. Table 2 maps the key features learners require on WawasanLearn to the key attractions of Facebook which increases the frequency of logins. 


\begin{tabular}{|c|c|c|}
\hline No & $\begin{array}{l}\text { Key features which would increase the } \\
\text { frequency of logins into WawasanLearn }\end{array}$ & The key attractions of Facebook \\
\hline 1 & A better user interface & $\begin{array}{l}\text { - User-friendly interface which is easy to } \\
\text { navigate. } \\
\text { - The ability to view the profiles of friends } \\
\text { and colleagues. } \\
\text { - The ability to follow the progress of friends } \\
\text { and colleagues with respect to research } \\
\text { and work. }\end{array}$ \\
\hline 2 & More quality discussions & $\begin{array}{l}\text { The ability to share images, links and } \\
\text { videos easily and the ability to receive } \\
\text { comments on them. } \\
\text { - The ability to interact with friends, } \\
\text { colleagues and family in a virtual space. } \\
\text { The ease of organising events and inviting } \\
\text { friends and colleagues to participate. }\end{array}$ \\
\hline 3 & Faster response time & \multirow{2}{*}{$\begin{array}{l}\text { - Instant updates via e-mails and SMS with } \\
\text { respect to related activities. }\end{array}$} \\
\hline 4 & $\begin{array}{l}\text { A proactive approach to discussions - } \\
\text { students receive an e-mail/SMS as soon } \\
\text { as a new message is posted }\end{array}$ & \\
\hline
\end{tabular}

Table 2 Mapping of the required features of WawasanLearn to the key attractions of Facebook

However, by analysing the findings from WOU's perspective, it was realised that Facebook alone would not be able to effectively serve the needs of the adult ODL students. Therefore, a hybrid approach, which marries the pedagogical soundness of the Moodle-based WawasanLearn with the social interactivity of Facebook, was needed. 


\section{WOU Facebook study groups}

A pilot project was initiated at WOU to study the feasibility of using Facebook as a supplement to WawasanLearn with the aim of increasing student satisfaction. Facebook study groups were formed for several IT-related courses in the School of Science and Technology (SST) as shown in Table 3.

\begin{tabular}{|c|c|c|c|c|}
\hline & Course code & Course name & Duration of FB study & No. of participants \\
\hline 1 & TCC222/05 & Operating Systems & 1 semester $(\mathrm{S} 1 / 2010)$ & 29 \\
\hline 2 & TEC305/10 & $\begin{array}{l}\text { Website Design and } \\
\text { Development }\end{array}$ & 1 semester $(\mathrm{S} 1 / 2010)$ & 07 \\
\hline 3 & TAI303/05 & $\begin{array}{l}\text { Intelligent Systems for } \\
\text { Decision Support }\end{array}$ & 1 semester $(\mathrm{S} 1 / 2010)$ & 05 \\
\hline 4 & TCC123/05 & Visual Programming & 1 semester (S2/2010) & 33 \\
\hline 5 & TAI201/05 & $\begin{array}{l}\text { Human Computer } \\
\text { Interaction }\end{array}$ & 1 semester $(\mathrm{S} 2 / 2010)$ & 21 \\
\hline 6 & TCC236/05 & $\begin{array}{l}\text { Data Structures and } \\
\text { Algorithms }\end{array}$ & 1 semester (S2/2010) & 12 \\
\hline 7 & TEC304/10 & Electronic Commerce & 1 semester (S2/2010) & 07 \\
\hline & \multicolumn{3}{|c|}{$\begin{array}{l}\text { Total number of participants over two semesters } \\
\text { (12 months) }\end{array}$} & 114 \\
\hline
\end{tabular}

Table 3 Facebook study groups

These study groups were systematically structured, as shown in Figure 4, to allow effective student interaction with course coordinators and tutors. The course coordinator in charge of a particular course module was assigned the role of administrator, which allowed him/her to moderate the postings, send out notifications to all group members, organise events and manage the member list. Tutors were also invited to join the group. Only the students enrolled in a particular course were allowed access to the study group for that course to ensure that discussions and postings were kept confidential. 


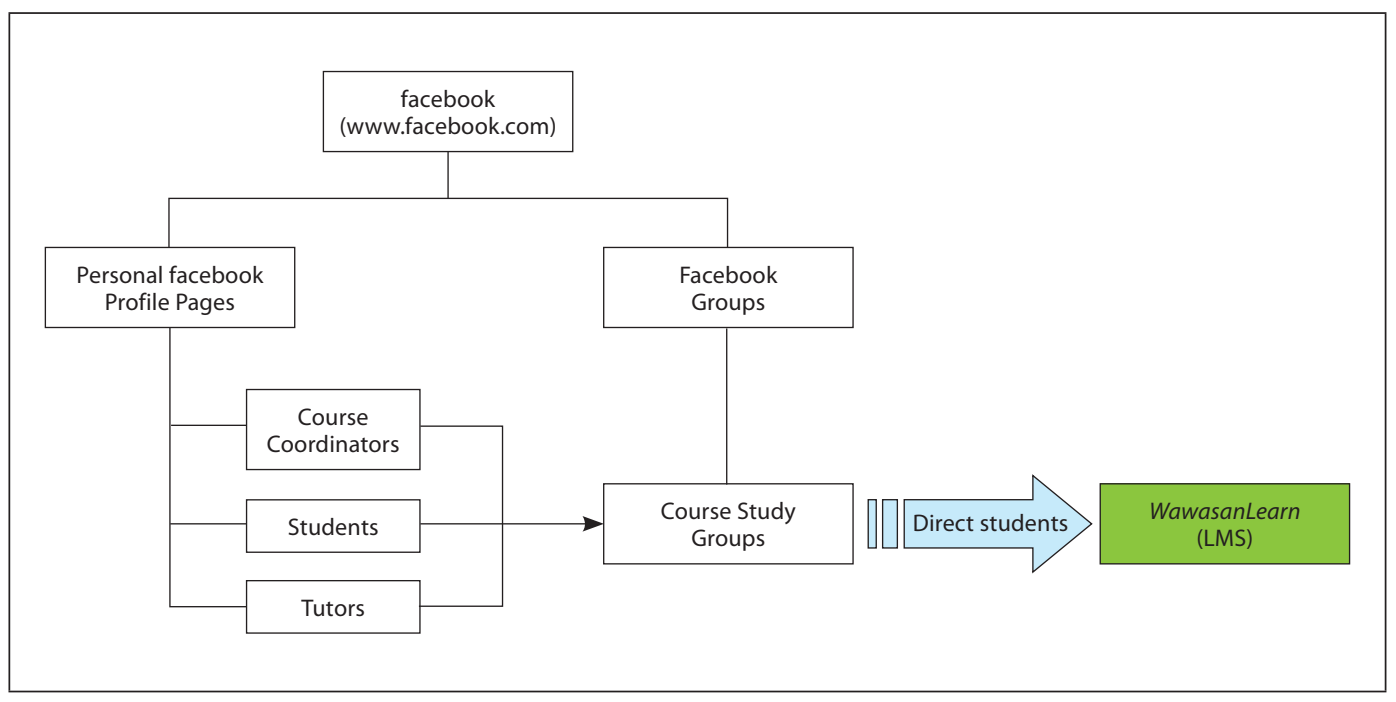

Figure 4 Structure of the Facebook study groups

Results of the pilot study showed that Facebook study groups can be very effective in supplementing WawasanLearn. However, the best results were achieved when the Facebook study groups were used as message boards to inform students of new developments, discussions or resources available on WawasanLearn. This approach encouraged the students to access the LMS more frequently due to the prompt communication, as a posting on the study group's "wall" appears instantly on a student's personal "wall". In addition, the "Message All Members" feature was used to send instant messages to the study group members about new developments on WawasanLearn. This "push-information" approach was found to be very effective as messages are forwarded instantly to the members' e-mail addresses in contrast to the "pull-information" approach of the LMS where learners need to proactively log in to retrieve information. The pilot study also confirmed that Facebook cannot be effectively used as a replacement for WawasanLearn due to its inherent limitations, such as the inability to host documents, presentations and multimedia materials, and legal implications. However, security and privacy were not found to be issues as the groups did not have access to the personal profiles of the learners.

A survey was conducted among the pilot project participants at the end of the second semester of 2010 to gather their feedback. The majority indicated that they would want to join Facebook study groups in the future but noted that they found it inefficient to switch between the two systems, namely WawasanLearn and Facebook, to keep up-to-date on the latest information regarding their course modules. The students further indicated that they preferred to use only Facebook to extract information available on WawasanLearn. As a result, a Facebook application called "faboodle" that will integrate WawasanLearn with Facebook is currently under development. 


\section{Conclusion}

Analysis of the data from several semesters indicated that the frequency of participation on the Moodle (ver.1.8)-based LMS of WOU called WawasanLearn was low. A study was conducted in the form of a survey among the adult ODL students at WOU to identify the factors which contributed to the frequency of logins into WawasanLearn. The study also aimed to identify the extent of the use of the Facebook social networking platform (facebook.com) by students and determine why they were drawn to participate more frequently on this social networking platform.

The analysis of the data identified several key features which would increase the frequency of logins into WawasanLearn. It further identified Facebook as an ideal supplement to WawasanLearn as the key features were already available on this platform. As a result, a pilot project was initiated in the School of Science and Technology which used Facebook groups as study groups to supplement WawasanLearn. The pilot project was run for two semesters over one year and feedback was gathered from the participants at the end of the project. The feedback indicated that the students found the Facebook study groups to be effective tools for their learning and that Facebook and WawasanLearn should be integrated instead of being run as two separate platforms. The next move for the authors is to implement a Facebook application which effectively integrates Facebook with WawasanLearn.

Ishan Sudeera Abeywardena (e-mail: ishansa@wou.edu.my) and Tham Choy Yoong (e-mail: cytham@wou.edu.my) are in the School of Science and Technology, Wawasan Open University, Penang, Malaysia

\section{Acknowledgments}

The authors wish to acknowledge the support provided by the directors as well as the staff of all Wawasan Open University regional offices in conducting the survey and gathering the responses.

\section{References}

Baird, D. E., \& Fisher, M. (2006). Neomillennial user experience design strategies utilizing social networking media to support "always on" learning styles. Journal of Educational Technology Systems, 34(1), 5-32.

Bates, T. (2001). The continuing evolution of ICT capacity: The implications for education. In G. M. Farrel (Ed.), The Changing Face of Virtual Education (pp. 29-46). Vancouver, Canada: The Commonwealth of Learning. 
Ellison, N. B., Steinfield, C., \& Lampe, C. (2007). The benefits of Facebook "friends:" Social capital and college students' use of online social network sites. Computer-Mediated Communication, 12, 1143-1168.

Macintyre, R., \& Macdonald, J. (2011). Remote from what? Perspectives of distance learning students in remote rural areas of Scotland. International Review of Research in Open and Distance Learning, 12(4), $1-16$.

Madgea, C., Meekb, J., Wellensc, J., \& Hooleyd, T. (2009). Facebook, social integration and informal learning at university: 'It is more for socialising and talking to friends about work than for actually doing work'. Learning, Media and Technology, 34(2), 141-155.

Mason, R., \& Weller, M. (2000). Factors affecting students' satisfaction on a web course. Australian Journal of Educational Technology, 16(2), 173-200.

Mazer, J. P., Murphy, R. E., \& Simonds, C. J. (2007). I'll see you on "Facebook": The effects of computer-mediated teacher self-disclosure on student motivation, affective learning, and classroom climate. Communication Education, 56(1), 1-17.

Ophus, J. D., \& Abbitt, J. T. (2009). Exploring the potential perceptions of social networking systems in university courses. MERLOT Journal of Online Learning and Teaching, 5(4), $639-648$.

Stacy, E. (2002). Social presence online: Networking learners at a distance. Education and Information Technologies, 7(4), 287-294.

Teoh, A. P., Aw, Y. C., \& Manoharan, K. (2010). Students' interaction in the online learning management systems: A comparative study of undergraduate and postgraduate courses. Proceedings of the $24^{\text {th }}$ Asian Association of Open Universities Annual Conference. Vietnam.

Wang, M., Sierra, C., \& Folger, T., (2003). Building a dynamic online learning community among adult learners. Education Media International, 49(1-2), 49-61. 